\title{
Correction of the structure of cuevaene A and its identity with MBJ-0020 from Streptomyces sp. 30503
}

\author{
Miho Izumikawa $^{1}$, Masashi Itoh ${ }^{2}$, Teppei Kawahara ${ }^{1}$, Noriaki Sakata ${ }^{2}$, Toshio Tsuchida ${ }^{2}$ and Kazuo Shin-ya ${ }^{3}$
}

The Journal of Antibiotics (2013) 66, 563-565; doi:10.1038/ja.2013.43; published online 8 May 2013

Keywords: cuevaene A; JBIR-23; Streptomyces

Malignant pleural mesothelioma (MPM), which is associated with exposure to asbestos fibers, is an aggressive neoplasm that develops in the pleura, and is highly invasive to surrounding tissues. ${ }^{1-3}$ In particular, MPM has been shown to be resistant to all conventional therapies, including chemotherapy, radiotherapy and surgery, leading to a very poor prognosis of MPM patients. Consequently, it is a tumor that continues to be a difficult clinical problem. ${ }^{1-3}$ Therefore, development of novel therapeutic agents against MPM is highly desirable.

In the course of our screening program for cytotoxic compounds against MPM derived from microbial metabolites, we isolated novel anti-MPM compounds designated as JBIR-23 and -24 from Streptomyces sp. AK-AB27 (Figure 1). ${ }^{4,5}$ Further screening resulted in the discovery of a compound, MBJ-0020 (compound 1), from the culture of Streptomyces sp. 30503 residing in the MBJ's special collection of microbial strains. Compound 1 was speculated to be cuevaene $\mathrm{A}^{6}$ according to its molecular formula, when analyzed with ultraperformance liquid chromatography coupled with time-of-flight MS. To confirm the structure of $\mathbf{1}$, we carried out the structure determination of $\mathbf{1}$ by a series of NMR analyses. The result showed us that the reported structure of cuevaene A was incorrect. Here, we report the isolation, structural elucidation and brief biological activity of 1 , and discuss the structural revision of cuevaene A.

The strain Streptomyces sp. 30503 was isolated from sponges collected in Okinawa Prefecture, Japan, according to the published method. ${ }^{7}$ The strain was cultivated in 250-ml Erlenmeyer flasks, each containing $25 \mathrm{ml}$ of a seed medium consisting of $2 \%$ potato starch (Tobu Tokachi Nosan Kako Agricultural Cooperative Assoc., Hokkaido, Japan), 2\% glucose (Junsei Chemical, Tokyo, Japan), $2 \%$ soy bean powder (Honen SoyPro, J-Oil Mills, Tokyo, Japan), $0.5 \%$ yeast extract powder (Oriental Yeast, Tokyo, Japan), $0.25 \%$ $\mathrm{NaCl}$ (Junsei Chemical), $0.32 \% \mathrm{CaCO}_{3} \quad$ (Wako Pure Chemical Industries, Osaka, Japan), $0.0005 \% \mathrm{CuSO}_{4} \cdot 5 \mathrm{H}_{2} \mathrm{O}$ (Wako Pure
Chemical Industries), $0.0005 \% \mathrm{ZnSO}_{4} \cdot 7 \mathrm{H}_{2} \mathrm{O}$ (Wako Pure Chemical Industries) and $0.0005 \% \quad \mathrm{MnCl}_{2} \cdot 4 \mathrm{H}_{2} \mathrm{O}$ (Junsei Chemical). The flasks were placed on a rotary shaker $\left(220\right.$ r.p.m.) at $28^{\circ} \mathrm{C}$ and incubated for 3 days. Measured aliquots $(0.5 \mathrm{ml})$ of the broth were then transferred to $500-\mathrm{ml}$ Erlenmeyer flasks containing $50 \mathrm{ml}$ of production medium of the same composition, and were cultured on a rotary shaker ( 220 r.p.m.) at $28^{\circ} \mathrm{C}$ for 4 days. The whole culture broth (21) was then extracted with $n$-butanol (2l).

After concentrating the extract in vacuo, the residual aqueous concentrate $(15.8 \mathrm{~g})$ was extracted with ethyl acetate (EtOAc) $(100 \mathrm{ml} \times 3)$. The separated organic layer was dried over $\mathrm{Na}_{2} \mathrm{SO}_{4}$ and concentrated in vacuo. The dried residue $(1.16 \mathrm{~g})$ was subjected to normal-phase medium-pressure liquid chromatography (Purif-Pack SI-30; Shoko Scientific, Yokohama, Japan), and was eluted stepwise by using a hexane-EtOAc solvent system (0, 5, 10, 20 and 25\% EtOAc) followed by a $\mathrm{CHCl}_{3}-\mathrm{MeOH}$ solvent system $(0,2,5,10$ and $20 \%$ $\mathrm{MeOH})$. The active eluate $(5 \% \mathrm{MeOH}, 380 \mathrm{mg})$ was subjected to reversed-phase medium-pressure liquid chromatography (Purif-Pack ODS-100), and was eluted stepwise by using a $\mathrm{H}_{2} \mathrm{O}-\mathrm{MeOH}$ solvent system $(40,60,80$ and $100 \% \mathrm{MeOH})$. The active eluate $(80 \% \mathrm{MeOH}$, $79 \mathrm{mg}$ ) was further purified by preparative reversed-phase HPLC by means of a Capcell Pak $\mathrm{C}_{18}$ MGII column $(5.0 \mu \mathrm{m}, 20$ i.d. $\times 150 \mathrm{~mm}$; Shiseido, Tokyo, Japan) with a Model 2996 photodiode array detector (Waters, Milford, MA, USA) and a Model 3100 mass detector (Waters), eluting with $75 \%$ aqueous $\mathrm{MeOH}$ containing $0.1 \%$ formic acid (flow rate, $10 \mathrm{ml} \mathrm{min}^{-1}$ ) to yield compound $\mathbf{1}$ (2.4 $\mathrm{mg}$, retention time $37.9 \mathrm{~min})$.

Compound 1 acquired this way was a colorless amorphous solid: $[\alpha]_{\mathrm{D}}^{26}+84.3(c 0.1, \mathrm{MeOH}) ; \mathrm{UV} \lambda_{\max } \mathrm{nm}(\log \varepsilon): 303$ (4.33), 258 (4.13) in $\mathrm{MeOH}$. The molecular formula was determined to be $\mathrm{C}_{21} \mathrm{H}_{22} \mathrm{O}_{5}$ by high-resolution ESI-MS (found: $353.1390[\mathrm{M}-\mathrm{H}]^{-}$, calculated: $\left.353.1389[\mathrm{M}-\mathrm{H}]^{-}\right)$. The presence of hydroxy and $\alpha, \beta$-unsaturated carboxylic acid functions was deduced from the

\footnotetext{
1Japan Biological Informatics Consortium (JBIC), 2-4-7 Aomi, Koto-ku, Tokyo, Japan; ²Bioresource Laboratories, MicroBiopharm Japan (MBJ), Iwata, Shizuoka, Japan and ${ }^{3}$ National Institute of Advanced Industrial Science and Technology (AIST), 2-4-7 Aomi, Koto-ku, Tokyo, Japan

Correspondence: Dr K Shin-ya, National Institute of Advanced Industrial Science and Technology (AIST), 2-4-7 Aomi, Koto-ku, Tokyo 135-0064, Japan.

E-mail: k-shinya@aist.go.jp
}

Received 23 January 2013; revised 8 April 2013; accepted 18 April 2013; published online 8 May 2013 
<smiles>COC(/C=C/C(=O)O)=C/C(C)=C/C1CCCc2oc3cc[14c](O)cc3c21</smiles>

MBJ-0020 (1)<smiles>COC(/C=C/C(=O)O)=C/C(C)=C/C1CCCc2c1oc1ccc(O)cc21</smiles>

originally proposed structure for cuevaene A

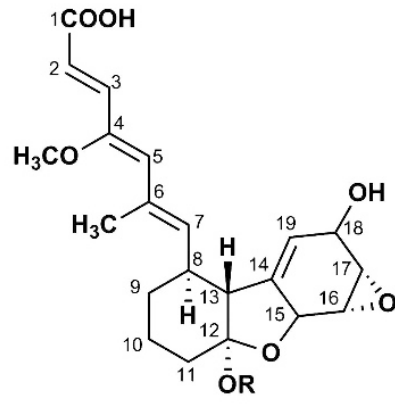

$\mathrm{R}=\mathrm{CH}_{3} \quad$ JBIR-23 $\mathrm{R}=\mathrm{H} \quad \mathrm{JBIR}-24$

b

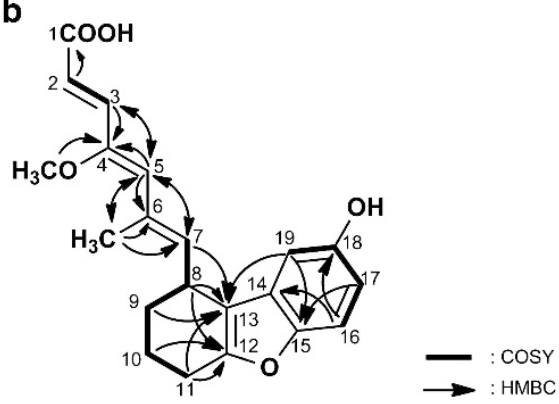

Figure 1 (a) Structures of MBJ-0020 (compound 1), originally proposed cuevaene $A^{6}$, JBIR -23 and -24 . (b) Correlations in DQF-COSY, TOCSY (bold lines) and CT-HMBC (arrows) spectra of compound $\mathbf{1}$ (revised structure of cuevaene A).

Table $1{ }^{13} \mathrm{C}(150 \mathrm{MHz})$ and ${ }^{1} \mathrm{H}(600 \mathrm{MHz})$ NMR spectroscopic data for compound 1

\begin{tabular}{|c|c|c|}
\hline No. & $\delta_{C}$ & $\delta_{H}($ multiplicity, J, in $\mathrm{Hz}$ ) \\
\hline 1 & 170.6 & - \\
\hline 2 & 115.8 & $6.03, d(15.5)$ \\
\hline 3 & 144.2 & $7.10, d(15.5)$ \\
\hline 4 & 151.7 & - \\
\hline 5 & 131.0 & $5.82, \mathrm{~s}$ \\
\hline 6 & 131.8 & - \\
\hline 7 & 140.1 & $5.76, \mathrm{~d}(10.0)$ \\
\hline 8 & 32.3 & 3.81 , dt $(10.0,3.2)$ \\
\hline \multirow[t]{2}{*}{9} & 29.8 & $2.00, \mathrm{~m}$ \\
\hline & - & $1.54, \mathrm{~m}$ \\
\hline \multirow[t]{2}{*}{10} & 21.4 & $2.05, \mathrm{~m}$ \\
\hline & - & $1.85, \mathrm{~m}$ \\
\hline 11 & 23.4 & $2.72, \mathrm{~m}$ \\
\hline 12 & 155.3 & - \\
\hline 13 & 114.5 & - \\
\hline 14 & 129.1 & - \\
\hline 15 & 149.3 & - \\
\hline 16 & 111.1 & $7.22, \mathrm{~d}(8.5)$ \\
\hline 17 & 111.2 & $6.66, \mathrm{dd}(8.5,1.7)$ \\
\hline 18 & 151.1 & \\
\hline 19 & 104.5 & $6.68, d(1.7)$ \\
\hline 4-OMe & 60.2 & $3.66, \mathrm{~s}$ \\
\hline 6-Me & 14.9 & $2.21, \mathrm{~s}$ \\
\hline
\end{tabular}

NMR spectra were obtained in $\mathrm{CDCl}_{3}$ using the Varian NMR system $600 \mathrm{NB} \mathrm{CL}$ (Palo Alto, CA, USA). The solvent peak was used as an internal standard $\left(\delta_{\mathrm{H}} 7.25\right.$ p.p.m. and $\delta_{\mathrm{C}} 77.0$ p.p.m.). compound's IR spectrum $\left(v_{\max } 3355,1681 \mathrm{~cm}^{-1}\right)$. The direct connectivity between protons and carbons was established by a HSQC spectrum. The ${ }^{13} \mathrm{C}$ and ${ }^{1} \mathrm{H}$ NMR spectroscopic data for compound $\mathbf{1}$ is shown in Table 1 . The structure elucidation of compound 1 by means of DQF-COSY and constant time-HMBC 8 spectra is described in the following section.

Three substructures were recognized by analyzing DQF-COSY and CT-HMBC. The ${ }^{1} \mathrm{H}-{ }^{1} \mathrm{H}$ spin correlation was observed between doublet olefinic protons $\mathrm{H}-2\left(\delta_{\mathrm{H}} 6.03\right)$ and $\mathrm{H}-3\left(\delta_{\mathrm{H}} 7.10\right)$. In the CT-HMBC spectrum, ${ }^{1} \mathrm{H}-{ }^{13} \mathrm{C}$ long-range couplings were observed from the olefinic protons $\mathrm{H}-2$ and $\mathrm{H}-3$ to a carboxylic carbon $\mathrm{C}-1$ $\left(\delta_{\mathrm{C}} 170.6\right)$ and a quaternary olefinic carbon $\mathrm{C}-4\left(\delta_{\mathrm{C}} 151.7\right)$, which in turn coupled to a methoxy proton $4-\mathrm{OCH}_{3}\left(\delta_{\mathrm{C}} 60.2, \delta_{\mathrm{H}} 3.66\right)$ and an olefinic proton $\mathrm{H}-5\left(\delta_{\mathrm{H}} 5.82\right)$. The singlet allylic methyl proton $6-\mathrm{Me}$ $\left(\delta_{\mathrm{H}} 2.21\right)$ was long-range-coupled to olefinic carbons C-5 $\left(\delta_{\mathrm{C}} 131.0\right)$, C-6 $\left(\delta_{\mathrm{C}} 131.8\right)$ and C-7 $\left(\delta_{\mathrm{C}} 140.1\right)$. These $2 \mathrm{D}$ NMR correlations and the absorption of an $\alpha, \beta$-unsaturated carboxylic acid at $1681 \mathrm{~cm}^{-1}$ in the IR spectrum revealed a 4-methoxy-6-methyl-hepta-2,4,6-trienoic acid moiety in compound $\mathbf{1}$ as shown in Figure $1 \mathrm{~b}$.

In addition to these resonances ascribed to the triene moiety, compound 1 showed 12 extra ${ }^{13} \mathrm{C}$ resonances. The sequence from an olefinic proton $\mathrm{H}-7\left(\delta_{\mathrm{H}} 5.76\right)$ to methylene protons $\mathrm{H}_{2}-11\left(\delta_{\mathrm{H}} 2.72\right)$ through a methine proton $\mathrm{H}-8\left(\delta_{\mathrm{H}} 3.81\right)$, methylene protons $\mathrm{H}_{2}-9$ $\left(\delta_{\mathrm{H}} 2.00,1.54\right)$ and $\mathrm{H}_{2}-10\left(\delta_{\mathrm{H}} 2.05,1.85\right)$ was established with the help of the DQF-COSY spectrum. The ${ }^{1} \mathrm{H}-{ }^{13} \mathrm{C}$ long-range couplings from both the methine proton $\mathrm{H}-8$ and the methylene protons $\mathrm{H}_{2}-11$ to an oxygenated olefinic quaternary carbon C-12 $\left(\delta_{\mathrm{C}} 155.3\right)$ and an olefinic quaternary carbon $\mathrm{C}-13\left(\delta_{\mathrm{C}} 114.5\right)$ showed that these carbons existed in a six-membered ring system. The ${ }^{1} \mathrm{H}-{ }^{1} \mathrm{H}$ correlation, 
together with the spin-coupling constants among aromatic protons $\mathrm{H}-16\left(\delta_{\mathrm{H}} 7.22\right), \mathrm{H}-17\left(\delta_{\mathrm{H}} 6.66\right)$ and $\mathrm{H}-19\left(\delta_{\mathrm{H}} 6.68\right)$ revealed a 1,3,4-trisubstituted benzene ring moiety. In addition, strong $m$-couplings from $\mathrm{H}-17$ and $\mathrm{H}-19$ to an aromatic quaternary carbon C-15 $\left(\delta_{\mathrm{C}} 149.3\right)$, and from $\mathrm{H}-16$ to an aromatic quaternary carbon C-14 $\left(\delta_{\mathrm{C}} 129.1\right)$ and $\mathrm{C}-18\left(\delta_{\mathrm{C}} 151.1\right)$ established the assignments of the benzene ring moiety. According to the typical ${ }^{13} \mathrm{C}$ chemical shifts of C-15 $\left(\delta_{\mathrm{C}} 149.3\right)$ and C-18 $\left(\delta_{\mathrm{C}} 151.1\right)$, these carbons were assigned to be oxygenated. Finally, the ${ }^{1} \mathrm{H}-{ }^{13} \mathrm{C}$ long-range coupling from the aromatic proton $\mathrm{H}-19$ to the olefinic quaternary carbon C-13 established the link between these two partial structures. By taking into consideration an unsaturated number obtained from the molecular formula of compound 1, a 6,7,8,9-tetrahydrodibenzo $[b, d]$ furan-2-ol moiety was established as shown in Figure $1 b$. In addition, treatment with TMS-diazomethane resulted in the production of a 1-COOMe derivative, which also confirms that C-1 consists of a carboxylic acid group.

The configurations of the triene side chain moiety in compound $\mathbf{1}$ were established to be $2 E, 4 Z$ and $6 E$ by the means of analyzing the proton spin-coupling constant between $\mathrm{H}-2$ and $\mathrm{H}-3(J=15.5 \mathrm{~Hz})$, and the strong NOESY correlations between $\mathrm{H}-3 / \mathrm{H} 5 \quad(2 E)$, $\mathrm{H}-5 / \mathrm{H}-7$ (4Z) and 4-OMe/6-Me (6E). We observed that the high-field-shifted ${ }^{13} \mathrm{C}$ chemical shift value at 6-Me $\left(\begin{array}{ll}\delta_{\mathrm{C}} & 14.9\end{array}\right)$ due to the $\gamma$-effect also supported the stereochemistry at C-6. Thus, the planar structure of compound $\mathbf{1}$ was determined as shown in Figure 1a.

The cytotoxic effects of compound 1 against various MPM cell lines were determined by a colorimetric assay with 2-(2-methoxy-4nitrophenyl)-3-(4-nitrophenyl)-5-(2,4-disulfophenyl)-2H-tetrazolium monosodium salt (WST-8, Cell Counting Kit; Dojindo, Kumamoto, Japan) for $48 \mathrm{~h}$. Compound 1 exhibited cytotoxic activities against three MPM cell lines, Meso-1, Meso-8A and Meso-8D with IC $_{50}$ values of 32, 40 and $78 \mu \mathrm{M}$, respectively. These cytotoxic effects were similar to those of JBIR-23 ( $\mathrm{IC}_{50}$ values of 31,39 and $111 \mu \mathrm{M}$, respectively). As compound $\mathbf{1}$ showed considerable effects on the MPM cell lines that demonstrate resistance to clinical anticancer drugs, it is expected to be an invaluable lead compound for developing anti-MPM drugs.

The structure of compound $\mathbf{1}$ differs from that reported for cuevaene $\mathrm{A}$ in the substitution position of the side chain on the tricyclic ring system of cuevaene A (corresponding to $\mathrm{C}-11$ position in compound 1). Cuevaene A, which displayed moderate antibacterial activity against Gram-positive bacteria, was isolated from Streptomyces sp. HKI $0180 .^{6}$ We have reported two structurally related compounds, named JBIR-23 and -24, isolated from the same species, which showed moderate cytotoxic effects against several MPM cell lines. ${ }^{4,5}$ All of these natural products embrace the tricyclic core and the triene side chain with an enol methyl ether. Although the structure of cuevaene A was originally proposed as shown in Figure 1a, we suggest that it is revised to that of compound $\mathbf{1}$ by altering the connective position of the triene side chain to the same site on the cyclohexane ring as that in JBIR-23 and -24, based on the extensive NMR correlations and the possible biosynthetic relationship among the compounds.

Recently, Liu et al. ${ }^{9}$ reported the syntheses of these two structures. The NMR spectra of the synthetic isomers are very similar to each other, and the published data for original cuevaene A do not match either isomer very well. On the other hand, Taylor et al. ${ }^{10}$ have just reported the total synthesis of cuevaene A with alternative structure. The NMR spectroscopic data of synthesized cuevaene A with revised structure corresponded with those of compound 1. Therefore, we revised the structure of cuevaene $\mathrm{A}$ as compound $\mathbf{1}$.

From a biosynthetic point of view, the structure of compound 1 seems to be quite plausible, because it presumably arises through the polyketide pathway utilizing a benzoic acid as a starter unit, in which the side chain moiety is substituted at the same position corresponding to JBIR-23 and JBIR-24. Studies on detailed biological activities including the mechanism of action and the biosynthesis of compound $\mathbf{1}$ are now under way.

\section{ACKNOWLEDGEMENTS}

This work was supported by a grant from the New Energy and Industrial Technology Department Organization (NEDO) of Japan and a Grant-in-Aid for Scientific Research (23380067 to K.S.) from the Japan Society for the Promotion of Science (JSPS).

1 Carbone, M., Kratzke, R. A. \& Testa, J. R. The pathogenesis of mesothelioma. Semin. Oncol. 29, 2-17 (2002).

2 Mossman, B. T., Kamp, D. W. \& Weitzman, S. A. Mechanisms of carcinogenesis and clinical features of asbestos-associated cancers. Cancer Invest. 14, 466-480 (1996).

3 Sekido, Y. Genomic abnormalities and signal transduction dysregulation in malignant mesothelioma cells. Cancer Sci. 101, 1-6 (2010).

4 Motohashi, K., Hwang, J.-H., Sekido, Y., Takagi, M. \& Shin-ya, K. JBIR-23 and -24, novel anticancer agents from Streptomyces sp. AK-AB27. Org. Lett. 11, 285-288 (2009).

5 Hwang, J.-H., Takagi, M., Murakami, H., Sekido, Y. \& Shin-ya, K. Induction of tubulin polymerization and apoptosis in malignant mesothelioma cells by a new compound JBIR-23. Cancer Lett. 300, 189-196 (2011).

6 Schlegel, B., Groth, I. \& Gräfe, U. Cuevaenes A and B, new polyene carboxyclic acids from Streptomyces sp. HKI 0180. J. Antibiot. 53, 415-417 (2000).

7 Khan, S. T. et al. Streptomyces associated with a marine sponge Haliclona sp.; biosynthetic genes for secondary metabolites and products. Environ. Microbiol. 13, 391-403 (2011).

8 Furihata, K. \& Seto, H. Constant time HMBC (CT-HMBC), a new HMBC technique useful for improving separation of cross peaks. Tetrahedron Lett. 39, 7337-7340 (1998).

9 Chen, Y., Huang, J. \& Liu, B. Total syntheses of the proposed structures of cuevaene A. Tetrahedron Lett. 51, 4655-4657 (2010).

10 Craven, P. G. E. \& Taylor, R. J. K. Total synthesis and structural confirmation of $( \pm)$-cuevaene A. Tetrahedron Lett. 53, 5422-5425 (2012). 